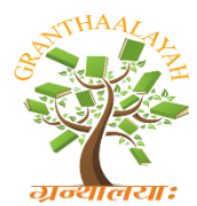

INTERNATIONAL JOURNAL OF RESEARCH -

GRANTHAALAYAH

A knowledge Repository

Science

\title{
IMAGING OF LUNG CANCER STAGING USING ADVANCED CT SCAN TECHNIQUES
}

\author{
Mwahib Sid Ahmed Aldosh ${ }^{1}$, Maha Esmeal Ahmed ${ }^{2}$ \\ ${ }^{1} \mathrm{Ph}$. D, Associate Professor, Applied Medical College, Radiological Sciences Department, \\ Najran University- Kingdom of Saudi Arabia \\ ${ }^{2} \mathrm{Ph}$. D, Associate Professor, Radiography and Medical Imaging Sciences, Radiological Sciences \\ College, National University- Sudan
}

\begin{abstract}
Background: Lung cancer is one of leading death worldwide, it begins when cells in the lung grow out of control and formed mass or nodules which classified in two known major forms, nonsmall cell and small cell cancer. The accurate assessment of the disease extent is important in management approach and Computed tomography imaging in nodal staging remains the important tool for lung cancer diagnosis, particularly when assessing intra and extra thoracic spread of lung cancer.

Objective: This is a quantitative cross-sectional study conducted in Sudanese lung cancer patients in period from November 2019 to February 2020 in Khartoum state hospital. The main aim of the study was to evaluate staging of lung cancer using computed tomography technology.

Method: A group of 100 participants patients were selected randomly in different gender and in age group between (30-80) years old. The inclusion limited to patients diagnosed with lung cancer by computed tomography techniques and the normal cases and other abnormalities was being excluded. The data were collected using a special collection sheet and the data statistical analyzed using SPSS program.

Result: The outcomes of this study showed that patients in age group between (60-70) years old do not have lung cancer in the first stage, while lung cancer in the second stage occurred in 10 patients only with $10 \%$ percentage. The third stage is the most common type with a high incidence rate which occurred in 90 patients with $90 \%$. Percent.

Conclusion: Advance imaging with CT scan techniques play a critical role in the diagnosis and management of lung cancer patients adding to accurately describing the radiological extent of the disease. Moreover, the important to understand the principles of staging description and their impact on treatment decisions.
\end{abstract}

Keywords: Lung Cancer; Staging; Computed Tomography; Imaging.

Cite This Article: Mwahib Sid Ahmed Aldosh, and Maha Esmeal Ahmed. (2020). "IMAGING OF LUNG CANCER STAGING USING ADVANCED CT SCAN TECHNIQUES." International Journal of Research - Granthaalayah, 8(3), 22-28. https://doi.org/10.29121/granthaalayah.v8.i3.2020.120. 


\section{Introduction}

Radiologic conventional chest x-ray, computed tomography (CT), magnetic resonance (MR) and positron emission tomography (PET) are all imaging techniques used for the detection staging and follow-up of lung cancer. Computed tomography scan for the chest is the cornerstone of lung cancer imaging and the success of CT is related to the fact that very detailed imaging information of the localization and the extent of the tumor also the presence of enlarged lymph nodes and the presence of metastatic disease can be provided.

The advantages of multi-detector CT scanners (MDCT) have revolutionized in the diagnostic approach to the lung cancer. This due to an increased temporal and spatial resolution, rabid Data acquisition that scanning of the entire lung can be performed within a single breath-hold, there is also a better contrast material administration possible also the continuous acquisition of thin slices allows the improvement of the image quality of multiplanar reconstruction (MPR) images (1) . Lung cancers primary tumor shows a wide spectrum of imaging appearances, the primary lung cancer in CT scan mages commonly have central location and masses of mediastinial structures have peripheral situation with irregular margin, they can be uniformly solid or with central necrosis and centrally situated tumors are more likely to be of squamous histology .Tumors with mixed density or with ground grass nodules and consolidation which are referred to as adenocarcinoma also can be seen clearly in CT scan imaging.

Solitary pulmonary nodules in asymptomatic lung cancer patients is incidentally detected, it is often seen as which can have varied imaging appearance in CT scan images (2).

Definition of lung cancer staging including the way of describing where the lung cancer is located and the staging of Non-Small Cell Lung Cancer in general described as that the earliest stage of NSCLC ( stage 0 ) also called carcinoma in situ, other stages range from I to IV . As a rule, the lower the number, the less the cancer has spread. A higher number, such as stage IV, means cancer has spread more (3). Stages of the cancer is found in the lung and in the lymph nodes in the middle of the chest, also described as locally advanced disease .Stage 1 refers to cancer confined to the lung only and has not spread to any lymph nodes, this type of staging is called clinical staging Stage II refers to the cancer is in the lung and nearby lymph nodes involves the regions of lungs hilar prebronchial and bronchopulmonary nods this stage called pathologic or surgical staging here the lung cancer staging determined the extent of disease in order to select patients who will benefit from surgery. Stage III refers to cancer is found in the lung and in the lymph nodes in the middle of the chest, also described as locally advanced disease, in this stage cancer spread to mediastinial nods or involving chest structures such as wall and precardium region. Stage IIII involves distant spread of the cancer on other organ of the body such as spread to brain, bones, adrenals and liver (3). The staging system for non-small cell lung cancer (NSCLC) including lung adenocarcinoma, squamous cell lung cancer, and large cell lung cancer staging described here is the system based on the values assigned to a patient's lung cancer in three categories including (tumor), (node), and (metastasis). The Small cell cancer type occurs almost exclusively in heavy smokers (4). The risk factors of lung cancer include family history, smoking, exposure to second hand smoke and exposure to radon gas, Lung cancer is the primary cancer in males and second in female , it accounting for $18 \%$ of total number of deaths and more than half of lung cancer patients have metastatic disease at presentation. Bones, adrenals, brain, and liver are the common distant 
metastatic sites. Metastatic disease with a few exceptions is not amenable to surgical resection or any kind of potentially curative therapy. Metastatic disease is further sub-classified as intra thoracic metastasis or extra thoracic metastasis, this is done due to differences in prognosis between the two categories. The intra thoracic metastasis were malignant and most common found in pleural spaces, pericardial region, and pulmonary nodules in the contralateral lung. And The extra thoracic metastasis includes spread to brain, bones, adrenals, liver, and any other distant extra-thoracic site (5). Computed tomography techniques have a big role in describing and diagnosis lung cancer. It is still the cornerstone of imaging studies in the preoperative staging and post-therapeutic evaluation of lung cancer. Were evaluation of CT examination in lung cancer screening can also include assessment of coronary calcification, emphysema and airway wall thickness biomarkers for major diseases that share risk factors with lung cancer $(6,7)$. The Diagnosis and staging of lung cancer in Small cell lung cancer usually presents at a relatively late stage and Non-small - cell lung cancer (NSCLC), constitutes $80 \%$ of diagnosed lung cancer (8). The overall 5-year survival for NSCLC is approximately $10 \%$ with over half harboring extra pulmonary spread at diagnosis. Stage is determined by tumors characteristics, nodal status and presence or absence of metastases $(9,10)$. Combining CT with positron emission tomography scanning or MRI allows targeted biopsies of suspicious nodes resulting in more accurate preoperative staging, now PET/CT or PET/MRI accepted as the standard procedure in the initial staging and diagnostic work-up of lung cancer patients. (11)

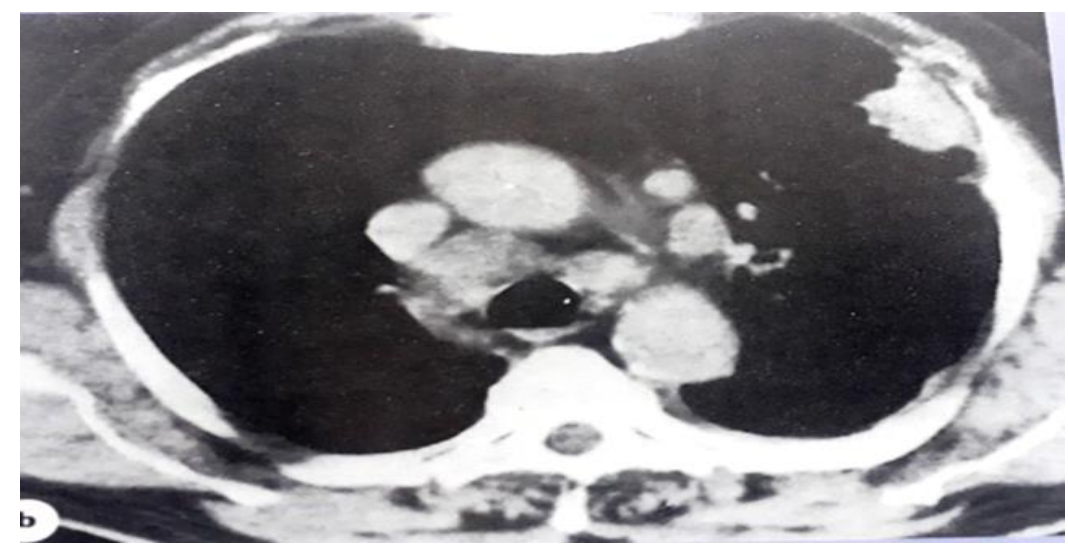

Figure 1: CT Scan adenocarcinoma

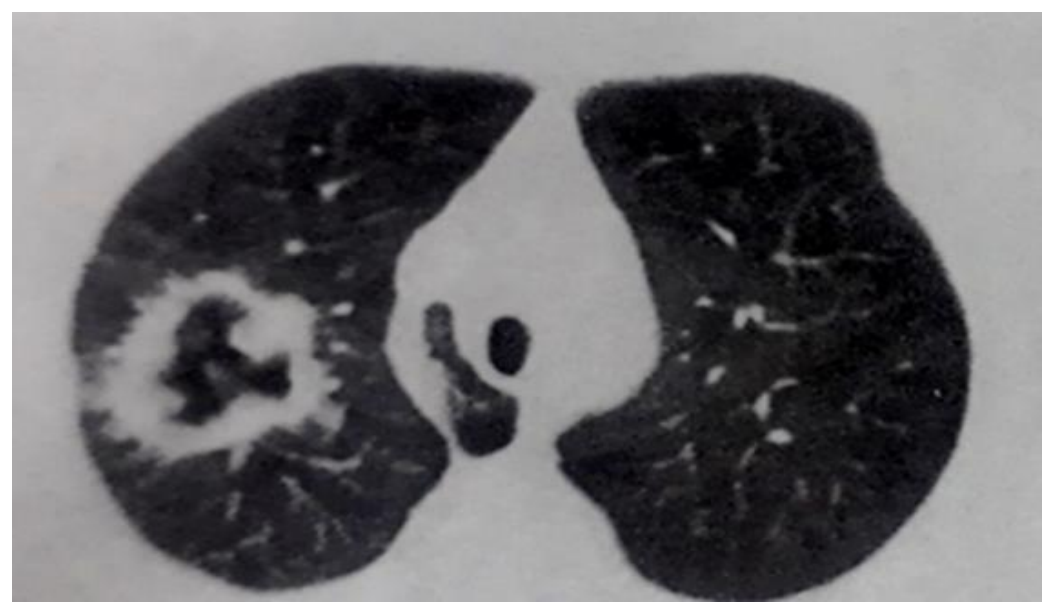

Figure 2: Axial CT scan demonstrate Squamous cell carcinoma 


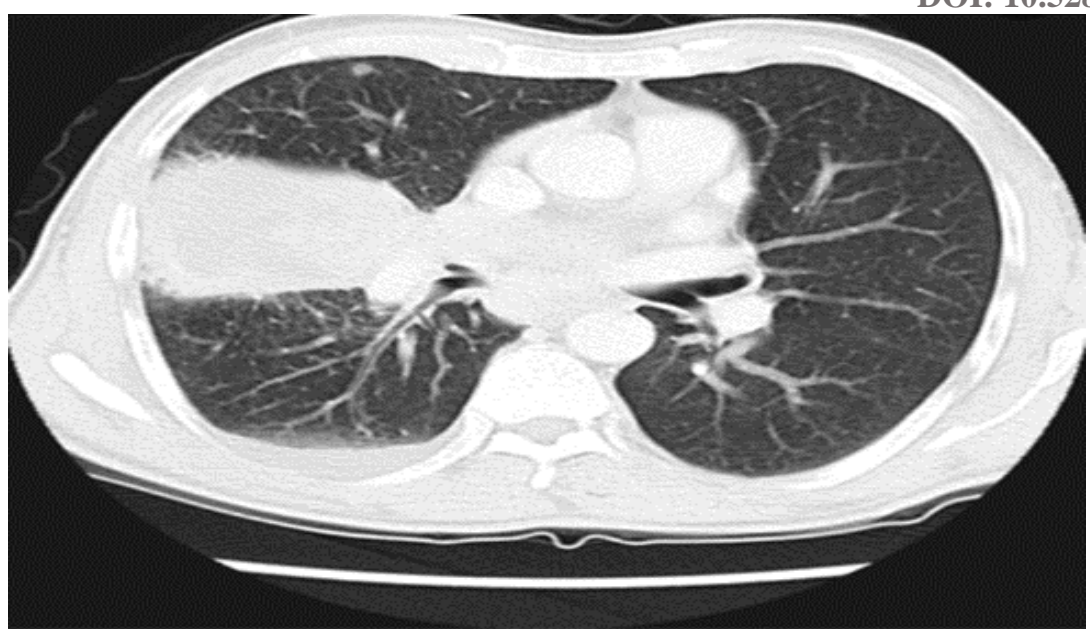

Figure 3: Axial CT scan shows large cell carcinoma

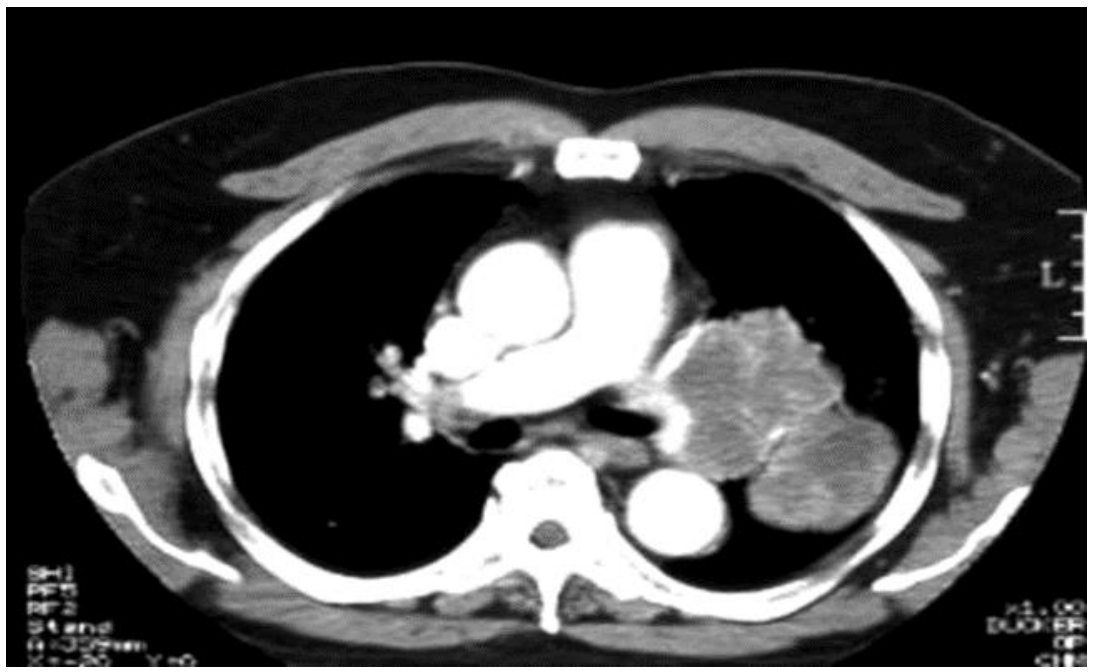

Figure 4: Shows Small cell carcinoma

\section{Material and Methods}

Methods: This a descriptive cross-sectional study conducted in Sudan - Khartoum state hospital. The data of the study were collected using a special sheet (closed questionnaire)

Samples of the study consisted of 100 participants were selective randomly in period from November 2019 to February 2020. The age group is between (30-80) years old. Excluded criteria including normal cases or patients affected with others diseases. The data were analyzed by using SPSS program version 23 which refer to (statistical package of social science).

Ethical Approval: Ethical approval has been granted from the hospital and the department of radiology were data did not include or disclose any [ID] information concerning the patient. Informed consent was obtained from all individual participants. 


\section{Results}

The following tables and figures present data that obtained from (100) patients who were examined by CT scan techniques.

Table 1: Distribution of patients according to their age

\begin{tabular}{|c|c|c|}
\hline Age & Frequency & Percent \\
\hline $31-40$ & 9 & 9 \\
\hline $41-50$ & 7 & 7 \\
\hline $51-60$ & 15 & 15 \\
\hline $61-70$ & 22 & 22 \\
\hline $71-80$ & 47 & 47 \\
\hline Total & 100 & 100.0 \\
\hline
\end{tabular}

Table 2: The distribution of patients according to the type of the lung cancer

\begin{tabular}{|c|c|c|}
\hline Lung cancer types & Frequency & Percent \\
\hline Small cell cancer & 30 & 30.0 \\
\hline Adenocarcinoma & 14 & 14.0 \\
\hline Squamous cell carcinoma & 12 & 12.0 \\
\hline Metastic tumor & 32 & 0.32 \\
\hline Large cell cancer & 6 & 6.0 \\
\hline NSL & 6 & 6.0 \\
\hline Total & 100 & 100.0 \\
\hline
\end{tabular}

Table 3: The distribution of patients according to the stage of the lung cancer

\begin{tabular}{|c|c|c|}
\hline Stage of lung cancer & Frequency & Percent \\
\hline Stage one & 13 & 13.0 \\
\hline Stage two & 45 & 45.0 \\
\hline Stage three & 42 & 42.0 \\
\hline Total & 50 & 100.0 \\
\hline
\end{tabular}

Table 4: The distribution of patients according to the lung cancer appearance

\begin{tabular}{|c|c|c|}
\hline Lung cancer appearances & Frequency & Percent \\
\hline Homogenous & 45 & 45 \\
\hline Heterogeneous & 55 & 55 \\
\hline Total & 50 & 100.0 \\
\hline
\end{tabular}

Table 5: Correlation between Gender and Stage of lung cancer

\begin{tabular}{|c|c|c|c|c|c|}
\hline & \multicolumn{3}{|c|}{ Stage of lung cancer } & \multirow[t]{2}{*}{ Total } \\
\hline & & \multicolumn{3}{|c|}{ Stage one Stage twoStage three } & \\
\hline \multirow[t]{2}{*}{ Sex Male } & Count & 8 & 14 & 28 & 50 \\
\hline & $\%$ within Sex & $16.0 \%$ & $28.0 \%$ & $56.0 \%$ & $100.0 \%$ \\
\hline \multirow[t]{2}{*}{$\overline{\text { Female }}$} & Count & 4 & 30 & 16 & 50 \\
\hline & $\%$ within Sex & $8.0 \%$ & $60.0 \%$ & $32.0 \%$ & $100.0 \%$ \\
\hline \multirow[t]{2}{*}{ Total } & Count & 12 & 44 & 34 & 100 \\
\hline & $\%$ within $\mathrm{Sex}$ & $12.0 \%$ & $44.0 \%$ & $44.0 \%$ & $100.0 \%$ \\
\hline
\end{tabular}




\section{Discussion}

The study found that from tables $(1,2,3,4,5)$ the distribution of patients according to their age the high incident age was from (71-80) years old (47\%), The patients with small cell carcinoma their frequency were $30(\% .30)$. The patients with adenocarcinoma, the frequency was $14(\% .14)$. The patients with sqamus cell carcinoma, their frequency was 12 (12) $\%$. The patients with metastes tumor their frequency was $32(32 \%)$. The patients with large cell cancer their frequency was 6 $(6 \%)$. The patients with non-small cell carcinoma, their frequency was $6(6 \%)$. The study achieved that according to the distribution of patients lung cancer stages, stage 1 their frequency were 13 (13\%), stage 2 their frequency 45(45\%), stage 3 their frequency 42(42\%). The study revealed that according to the distribution of patient's lung cancer appearance homogenous appearance of lung cancer was 45(45) \% and the heterogeneous appearances $55(55 \%)$. The study achieved that according to the distribution of stage of lung cancer based on gender The stage 1 of the male were $8(16 \%)$, and stage 2 of the male were $14(28 \%)$, stage 3 of the male were $28(56 \%)$. The stage 1 of the female were $4(8 \%)$, and stage 2 of the female were $30(60 \%)$, stage 3 of the female their frequency were 16(32\%). The study agree with previous study done in East North Africa achieved that when the patient was old there's high risk factor to have alung cancer so the probability of lung cancer increase with age (12). This study agrees with the previous study done in United Kingdom included males and females smoker found that the lung cancer increase in males more than females.

\section{Conclusion}

Advance imaging with CT scan techniques play a critical role in the diagnosis and the management of lung cancer patients, where in addition to its accuracy in describing the radiological extent of the disease, it is also have an importance in understanding the principles of staging, the clinical relevance staging description and their impact on treatment decisions.

The study found that the older patients have a high-risk factor to have a lung cancer and the probability of lung cancer increase with age increase.

\section{Reference}

[1] Kalra MK, Maher MM, D'Souza R, et al. Multidetector computed tomography technology: current status and emerging developments. J Comput Assist Tomogr 2004; 28 Suppl. 1:S2-S6

[2] Buccheri G, Ferrigno D. Lung cancer: Clinical presentation and specialist referral time. Eur Respir J. 2004; 24:898-904.

[3] Cancer Staging. American Cancer Society website. https://www.cancer.org/treatment/understanding-your-diagnosis/staging. Revised March 25, 2015. Accessed July 18, 2018.

[4] Kay FU, Kandathil A, Batra K, et al. Revisions to the tumor, node, metastasis staging of lung cancer (8th edition): rationale, radiologic findings and clinical implications. World Journal of Radiology. 2017 Jun 28:9(6):269-279

[5] Goldstraw P, Crowley J, Chansky K, Giroux DJ, Groome PA, Rami-Porta R, et al. The IASLC lung cancer staging project: Proposals for the revision of the TNM stage groupings in the forthcoming (seventh) edition of the TNM classification of malignant tumours. J Thorac Oncol. 2007; 2:70614. 
[6] Kim, Susan, Scott, Heddwen, 2010, Gannon's review of medical physiology, 23, Mc Graw-hill companies, 110-176)

[7] Edward Arnold, 2008, Muurs textbook of pathology, 159-188

[8] W.b Saunders, 1996, Radiology pathology,17(123-140)

[9] Mosby, 2007, Comprehensive radiographic pathology, elsevier 39-40

[10] Bontrager, lampignano, 2007. Human physiology for dental students, 5, Elsevier. 273-294

[11] Ricard 1. Drake, A. Wayne vogl, Adam w. M.mirchwl, 2014, Textbook of Radiographic Positioning and related anatomy,8(699)

[12] N.Hollings. P.Shaw, 2002, Diagnostic imaging of lung cancer, 7, European Respiratory Journal, 7. (723-726).

*Corresponding author.

E-mail address: maha_esmeal@yahoo.com 